\begin{tabular}{|c|c|}
\hline Title & Synthesis and study of the pancreatic a -amylase inhibitory activity of methyl acarviosin and its derivatives \\
\hline Author(s) & Kato, Eisuke; Chikahisa, Fumiaki; Kawabata, Jun \\
\hline Citation & $\begin{array}{l}\text { Tetrahedron Letters, } 57(12), 1365-1367 \\
\text { https://doi.org/10.1016/.tetlet.2016.02.053 }\end{array}$ \\
\hline Issue Date & $2016-03-23$ \\
\hline Doc URL & http://hdl .handle.net/2115/68675 \\
\hline Rights & $\begin{array}{l}\text { (ㅇ [2016]. This manuscript version is made available under the CC-BY-NC-ND } 4.0 \text { license } \\
\text { http://reativecommons.org/icenses/by-nc-nd/4.0/ }\end{array}$ \\
\hline Rights(URL) & https:/creativecommons.org/icenses/by-nc-nd/4.0/ \\
\hline Type & article (author version) \\
\hline Additional Information & There are other files related to this item in HUSCAP. Check the above URL. \\
\hline File Information & TL2016_57_1365-1367_HUSCAP.pdf \\
\hline
\end{tabular}

Instructions for use 
Author's post-print manuscript of the following article

Synthesis and study of the pancreatic a-amylase inhibitory activity of methyl acarviosin and its derivatives

Eisuke Kato; Fumiaki Chikahisa, Jun Kawabata

Tetrahedron Letters 2016, 57, 1365-1367

DOI:10.1016/j.tetlet.2016.02.053 


\title{
Synthesis and study of the pancreatic $\alpha$-amylase inhibitory activity of methyl acarviosin and its derivatives
}

\author{
Eisuke Kato*, Fumiaki Chikahisa, Jun Kawabata \\ Laboratory of Food Biochemistry, Division of Applied Bioscience, Graduate School of Agriculture, Hokkaido University, Kita-ku, Sapporo, Hokkaido 060-8589, \\ Japan \\ *Corresponding author. Tel.: +81-11-706-2496; fax: +81-11-706-2496; e-mail: eikato@chem.agr.hokudai.ac.jp
}

\section{ARTICLE INFO}

\section{Article history:}

Received

Received in revised form

Accepted

Available online

\section{Keywords:}

Pancreatic $\alpha$-amylase

$\alpha$-amylase inhibitor

diabetes mellitus

acarviosin

transglycosylation

\section{ABSTRACT}

Pancreatic $\alpha$-amylase is a target for type 2 diabetes mellitus treatment. However, small molecule inhibitors of $\alpha$-amylase are currently scarce. In the course of developing small molecule $\alpha$-amylase inhibitors, we designed and synthesized conjugates of glucose and acarviosin. The synthetic compounds showed mild $\alpha$-amylase inhibitory activity with higher activity compared with nonglucose conjugated compounds, but lower activity compared to acarviosin. Comparison of these activities revealed transglycosylation of acarviosin during the enzyme reaction. Additionally, the $\alpha-$ amylase inhibitory activity of acarviosin is expressed through these transglycosylation products.

2009 Elsevier Ltd. All rights reserved.
Type 2 diabetes mellitus (T2DM) is a metabolic disease that develops through either impaired insulin secretion or decreased insulin sensitivity. ${ }^{1}$ Insulin is a peptide hormone that functions to decrease gluconeogenesis, enhance glucose utilization and lower the blood glucose level. ${ }^{2}$ Failure in insulin's function therefore results in uncontrolled blood glucose levels that cause chronic high blood glucose levels. This is particularly problematic after food consumption, because absorption of food derived saccharides is the main process that rapidly elevates the blood glucose level.

Pancreatic $\alpha$-amylase (EC 3.2.1.1) is an enzyme that catalyzes hydrolysis of starch, the 1,4-connected poly- $\alpha$-D-glucose. Carbohydrate is an essential nutrient included in foods and starch is the major source of this nutrient. For absorption of starch into the body, hydrolysis of starch by $\alpha$-amylase together with other intestinal glucosidases is an essential process. Thus, the enzyme is important for the body. Since $\alpha$-amylase functions as a key enzyme for the digestion and absorption of starch, it can also be a target for the treatment of T2DM.

Inhibitors of $\alpha$-amylase function by modulating the blood glucose level after a meal. Acarbose, the tetrasaccharide mimic with potent $\alpha$-amylase inhibitory activity is employed in the current treatment of T2DM. ${ }^{3}$ A number of $\alpha$-amylase inhibitors have been identified from nature and reported; ${ }^{4-9}$ however, potent and selective $\alpha$-amylase inhibitors remain scarce.

We are working to develop novel $\alpha$-amylase inhibitors by modification of $\alpha$-glucosidase inhibitors. We reported previously the synthesis and $\alpha$-amylase inhibitory activity of glucose- deoxynojirimycin conjugates and their $\alpha$-amylase inhibitory activity. ${ }^{10}$ The addition of a glucose moiety through a hydrophobic linker increased the $\alpha$-amylase inhibitory activity of deoxynojirimycin, thus showing the potential of this method to prepare useful $\alpha$-amylase inhibitors.

Here, as a continuation of the previous report, ${ }^{10}$ we conjugated glucose to acarviosin, ${ }^{11,12}$ the core structure of acarbose with potent $\alpha$-glucosidase inhibitory activity, to test the generality of our previous finding to enhance $\alpha$-amylase inhibitory activity of $\alpha$-glucosidase inhibitors.

Glucose-acarviosin conjugates were designed and synthesized following the structure and synthesis of a glucosedeoxynojirimycin conjugate (Scheme 1). ${ }^{10}$ A mixture of methyl $\alpha$ - and $B$-acarviosin, prepared from acarbose by methanolysis, ${ }^{13}$ was reacted with 2,2-dimethoxypropane and then purified by silica-gel column chromatography to obtain the pure $\alpha$-anomer. The obtained isopropylidene protected methyl $\alpha$-acarviosin was hydrolyzed, reacted with $\alpha, \alpha$-dimethoxytoluene, and partial hydrolysis of the obtained multi-benzylacetal compound gave 4,6-benzylacetal (2). Hydroxyl groups of 2 were then reacted with $p$-methoxybenzyl chloride to give 3 . Benzylacetal was removed from $\mathbf{3}$ under acidic conditions and the resulting primary hydroxyl group was protected by the triisopropylsilyl group to give 4. Iodoalkyl glucoses 5a-c, prepared independently (see supporting information), were reacted with $\mathbf{4}$ and the resulting product was deprotected by trifluoroacetic acid to yield the desired products (6-8). Additionally, compound 9 was synthesized from 4 , which has no glucose moiety and the shortest alkyl chain (Scheme 2). 

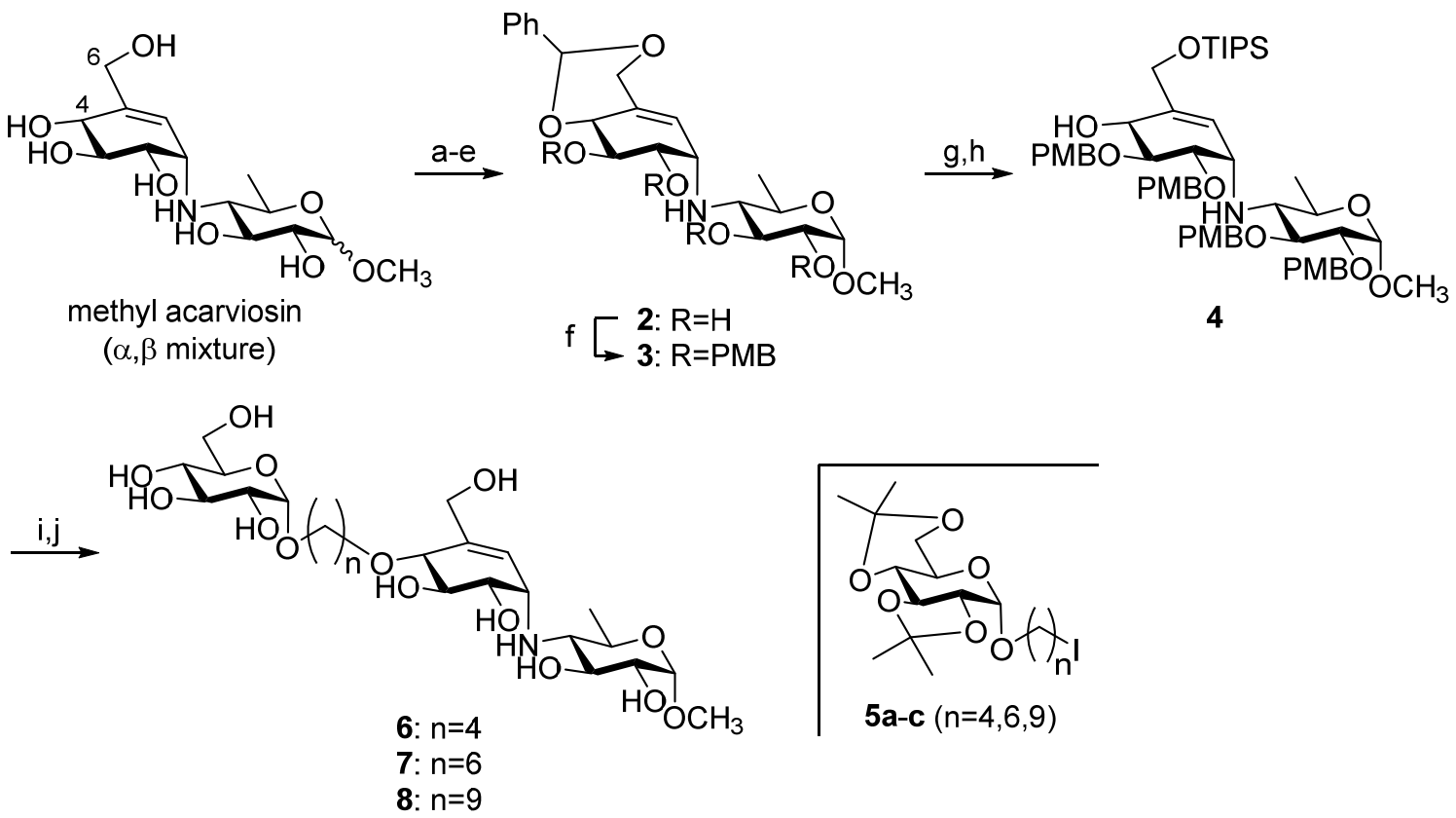

Scheme 1. (a) 2,2-dimethoxypropane, DMF, CSA; (b) separation of the $\alpha$-anomer, $18 \%$ in two steps; (c) $80 \%$ AcOH aq, 1,4 -dioxane; (d) $\alpha, \alpha$-dimethoxytoluene, CSA, DMF; (e) $40 \% \mathrm{AcOH}$ aq, 1,4-dioxane, 42\% in three steps; (f) PMBCl, $\mathrm{NaH}, \mathrm{DMF}, 56 \%$; (g) $80 \%$ AcOH aq, 1,4-dioxane, $50{ }^{\circ} \mathrm{C}$; (h) TIPSCl, imidazole, $\mathrm{CH}_{2} \mathrm{Cl}_{2}, 65 \%$ in two steps; (i) 5, NaH, DMF, THF, 15-25\%; (j) TFA, MeOH, quant.

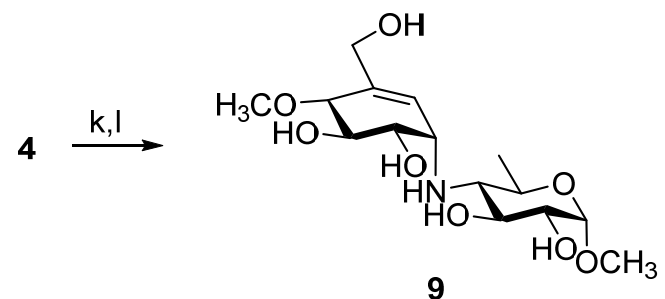

Scheme 2. (k) $\mathrm{CH}_{3} \mathrm{I}, \mathrm{NaH}, \mathrm{DMF}, \mathrm{THF}, 75 \%$; (l) TFA, MeOH, $92 \%$.

The $\alpha$-amylase inhibitory activities of the synthetic compounds are summarized in Table 1. Methyl $\alpha$-acarviosin (1) showed mild $\alpha$-amylase inhibitory activity at $500 \mu \mathrm{M}$ and strong inhibition at $2 \mathrm{mM}$. In contrast, the synthetic compounds (6-8) showed scarce or no inhibition at $500 \mu \mathrm{M}$ and mild inhibitory activity at $2 \mathrm{mM}$.

Unlike the previously synthesized glucose-deoxynojirimycin conjugate, no enhancement of $\alpha$-amylase inhibitory activity was observed for any of the synthetic compounds when compared with the inhibitory activity of $\mathbf{1}$. However, when the activity of 6-8 is compared with 9, clear enhancement is observed, indicating the effect of glucose addition. Thus, our concept to enhance $\alpha$-amylase inhibitory activity through conjugation of glucose is still effective. Therefore, we postulate that for the activity of $\mathbf{1}$, the free hydroxyl group at the C-4 position of acarviosin may have some function in the $\alpha$-amylase inhibitory activity, and derivatization using this residue decreases its activity.

In the case of acarbose, the hydroxyl group at the $\mathrm{C}-4$ position is known to participate in the transglycosylation reaction and produces a product with stronger affinity to $\alpha$-amylase during the enzyme reaction. ${ }^{14}$ To test if a similar reaction occurs for $\mathbf{1}$, we analyzed the enzyme reaction mixture. Analysis of the reaction mixture by UPLC-Tof-MS (Supplementary Figure 1) showed two peaks, the minor peak with $\mathrm{m} / \mathrm{z} 498.2179$ ([1+glucose$\left.\mathrm{H}_{2} \mathrm{O}+\mathrm{H}\right]^{+}, \mathrm{C}_{20} \mathrm{H}_{36} \mathrm{NO}_{13}$ requires $\mathrm{m} / \mathrm{z}$ 498.2187) and the major peak with $660.2714\left(\left[1+\text { maltose- } \mathrm{H}_{2} \mathrm{O}+\mathrm{H}\right]^{+}, \mathrm{C}_{26} \mathrm{H}_{46} \mathrm{NO}_{18}\right.$ requires $\mathrm{m} / \mathrm{z}$ 660.2715), which corresponds to the transglycosylation products of 1 (Figure 1A). Similar transglycosylation products were also detected from the analysis of enzyme reaction mixture of 6-8, except glucose transferred products were more abundant (Supplementary Figure 2-4). No transglycosylation products were detected for 9 (Supplementary Figure 5).

\section{Table 1}

$\alpha$-Amylase inhibitory activity of glucose-acarviosin conjugates

\begin{tabular}{|c|c|c|}
\hline \multirow[b]{2}{*}{ Compound } & \multicolumn{2}{|c|}{ Inhibitory activity (\%) } \\
\hline & $0.5 \mathrm{mM}$ & $2.0 \mathrm{mM}$ \\
\hline Methyl $\alpha$-acarviosin (1) & 65 & 85 \\
\hline $6(n=4)$ & 4 & 45 \\
\hline $7(n=6)$ & 2 & 43 \\
\hline $8(n=9)$ & 5 & 43 \\
\hline $9(n=1$, without glucose $)$ & 0 & 5 \\
\hline Acarbose $(5 \mu \mathrm{M})$ & \multicolumn{2}{|c|}{55} \\
\hline
\end{tabular}

From these results, $\alpha$-amylase inhibition of the tested compounds is summarized as followings. Methyl $\alpha$-acarviosin (1) itself has low affinity towards $\alpha$-amylase. However, during the enzyme reaction, 1 undergoes the transglycosylation reaction to form maltose or glucose attached products. These products mimic trisaccharides or tetrasaccharides and occupy one or two additional subsites of $\alpha$-amylase when compared with 1 . The subsite is a part of the substrate binding site of $\alpha$-amylase that interacts with a single glucose unit. ${ }^{15} \alpha$-Amylase shows strong affinity towards starch by interacting with multiple glucose units with multiple subsites and therefore, the transglycosylation 


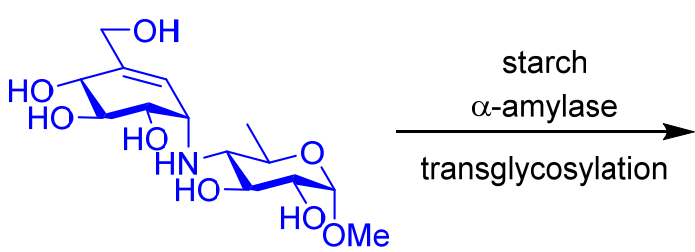

methyl $\alpha$-acarviosin (1)

Interact with two subsites

Low affinity

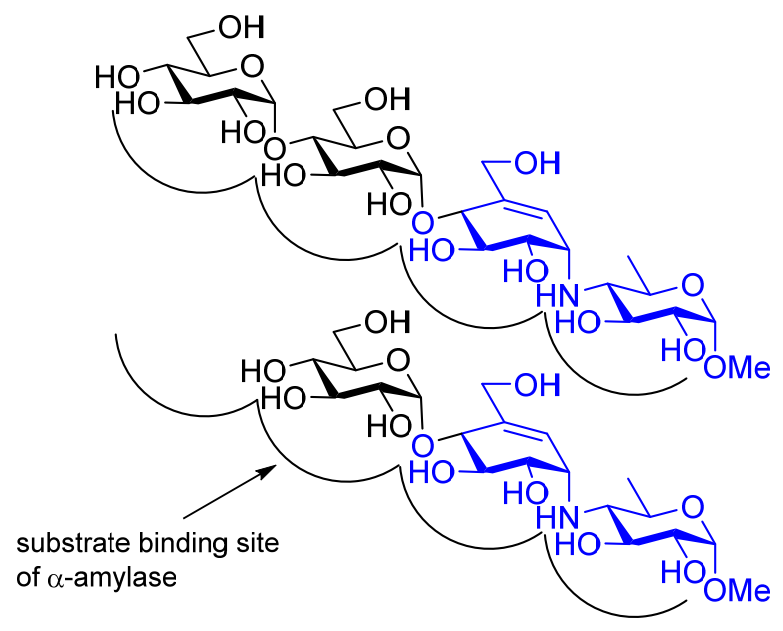

Additional interaction by added glucose Interact with three to four subsites High affinity
(B)

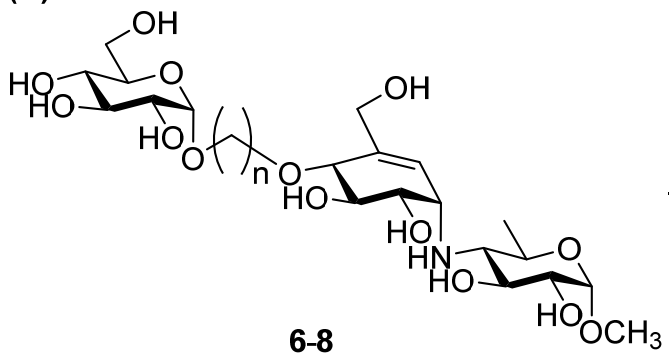

(C)

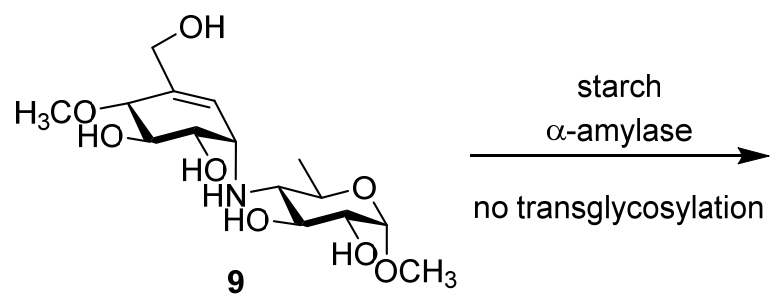

starch

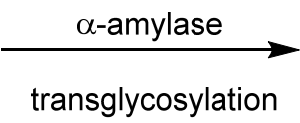

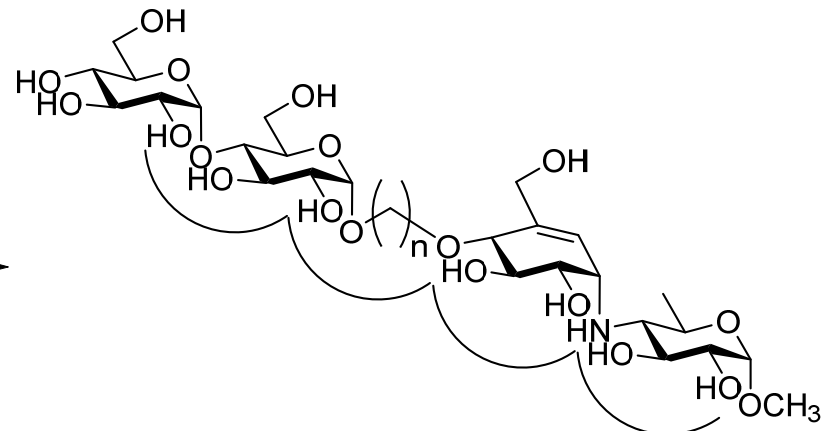

No additional interaction by added glucose Interact with three subsites (bypassing one subsite) Mild affinity

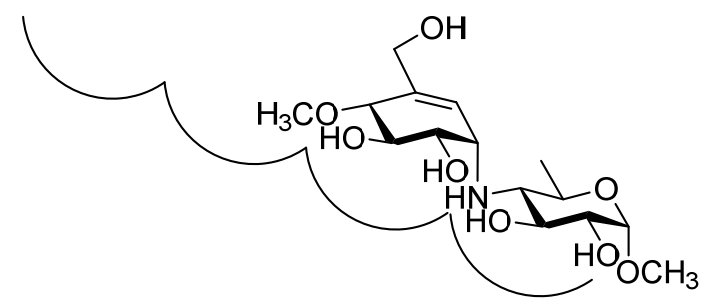

Interact with two subsites Low affinity

Figure 1. Binding of the inhibitors by $\alpha$-amylase. (A) Methyl $\alpha$-acarviosin reacts with starch through transglycosylation by $\alpha$-amylase. The transglycosylation products have high affinity towards $\alpha$-amylase. (B) Compounds $\mathbf{6}-\mathbf{8}$ undergo the transglycosylation reaction but the reaction has low effect on inhibition. (C) Compound $\mathbf{9}$ does not receive the transglycosylation reaction.

can yield products that show stronger inhibitory activity (Figure 1A). In comparison, compound $\mathbf{9}$ does not receive transglycosylation reaction because the C-4 hydroxyl group is not readily accessible, and the inhibitory activity of this compound results from their original structure (Figure 1C). Compound 6-8 are susceptible to transglycosylation reaction. However, the reaction have lower effect on the inhibitory activity since there are only two subsites above the acarviosin binding position, ${ }^{14}$ and additional glucose is not recognized by $\alpha$ amylase enzyme (Figure 1B). Therefore, the glucose-acarviosin conjugates (6-8) or their transglycosylation products interact with three subsites, thus bypassing one in the middle and $\mathbf{9}$ interacts with two subsites. Thus glucose-acarviosin conjugates show higher activity compared with 9; however, all synthetic compounds show lower activity compared with $\mathbf{1}$, because the transglycosylation products of $\mathbf{1}$ interact with more subsites.

In conclusion, we have synthesized glucose-acarviosin conjugates and tested their $\alpha$-amylase inhibitory activity. Our concept to enhance $\alpha$-amylase inhibitory activity by conjugating glucose to $\alpha$-glucosidase inhibitors was proven to have some effect when compared 6-8 with 9. In addition, we found that the $\alpha$-amylase inhibitory activity of methyl acarviosin arises from transglycosylation products.

\section{Acknowledgments}


The authors thank Mr. Yusuke Takata and Dr. Eri Fukushi of the GC-MS and NMR Laboratory, Faculty of Agriculture, Hokkaido University, for their skillful measurement of mass spectra.

\section{Supplementary data}

Detailed experimental procedures, compound data and UPLCTof-MS data.

\section{References and notes}

1. Hameed, I.; Masoodi, S. R.; Mir, S. A.; Nabi, M.; Ghazanfar, K.; Ganai, B. A. World J. Diabetes 2015, 6, 598.

2. Saltiel, A. R.; Kahn, C. R. Nature 2001, 414, 799

3. Krentz, A. J.; Bailey, C. J. Drugs 2005, 65, 385.

4. Yonemoto, R.; Shimada, M.; Gunawan-Puteri, M. D. P. T.; Kato, E.; Kawabata, J. J. Agric. Food Chem. 2014, 62, 8411.

5. Gunawan-Puteri, M. D. P. T.; Kato, E.; Kawabata, J. J. Sci. Food Agric. 2012, 92, 606 .

6. Williams, L. K.; Zhang, X.; Caner, S.; Tysoe, C.; Nguyen, N. T.; Wicki, J.; Williams, D. E.; Coleman, J.; McNeill, J. H.; Yuen, V.; Andersen, R. J.; Withers, S. G.; Brayer, G. D. Nat. Chem. Biol. 2015, 11, 691 .

7. Tarling, C. A.; Woods, K.; Zhang, R.; Brastianos, H. C.; Brayer, G. D.; Andersen, R. J.; Withers, S. G. Chembiochem 2008, 9, 433.

8. Vértesy, L.; Oeding, V.; Bender, R.; Zepf, K.; Nesemann, G. Eur. J. Biochem. 1984, 141, 505.

9. Murao, S.; Goto, A.; Matsui, Y.; Ohyama, K. Agric. Biol. Chem. 1980, 44, 1679.

10. Kato, E.; Iwano, N.; Yamada, A.; Kawabata, J. Tetrahedron 2011, 67, 7692 .

11. Ogawa, S.; Kosuge, Y.; Yasuda, K.; Mizukoshi, T.; Uchida, C. J. Chem. Soc. Chem. Commun. 1990, 50, 1387.

12. Shibata, Y.; Kosuge, Y.; Mizukoshi, T.; Ogawa, S. Carbohydr. Res. 1992, 228, 377.

13. Junge, B.; Heiker, F.-R.; Kurz, J.; Müller, L.; Schmidt, D. D.; Wünsche, C. Carbohydr. Res. 1984, 128, 235.

14. Qian, M.; Haser, R.; Buisson, G.; Duee, E.; Payan, F. Biochemistry 1994, 33, 6284 .

15. Robyt, J. F.; French, D. Arch. Biochem. Biophys. 1970, 138, 662. 